\section{Onze arquivos rubro-negros}

\section{Rafael Fava Belúzio}

O cronista acolheu com muito entusiasmo o apelo da editoria da revista FuLiA/UFMG de nos enviar uma crônica em homenagem ao sensacional Flamengo, seu time desde a infância, recentemente campeão da Libertadores e do Brasileirão.

Após a derrota no Mundi-

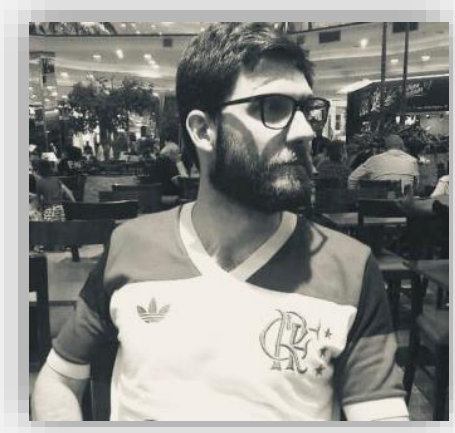

al de Clubes disputado pelos brasileiros, no Qatar, contra o Liverpool, endereçou-nos um instigante inédito. "Onze arquivos rubro-negros", inventivo texto/colagem, encena, em 11 fragmentos, os bastidores da crônica, e aposta na oralidade da escrita, nas "anotações" e nos breves contatos entre autor e editor, sobretudo por meio da intertextualidade com a playlist dedicada ao Flamengo. Esse texto, que tensiona habilidosamente gêneros literários e afetos, aborda a equipe mais popular do Brasil (e suas contradições), igualmente, com a maestria e a intensidade de um "Camisa 10 da Gávea".
Rafael nasceu em Carangola/MG, Zona da Mata, em 1985. Graduou-se em Letras pela Universidade Federal de Viçosa e realizou mestrado e doutorado em Estudos Literários pela Universidade Federal de Minas Gerais. Já publicou mais de duzentas crônicas, atuando no jornal $O$ Interior (2005-2013) e no Jornal da Cidade (2012-2015), ambos de sua terra natal. É autor do livro Uma lira de duas cordas: 0 ritmo como elemento construtivo da binomia de Lira dos vinte anos (Belo Horizonte: Scriptum, 2015).

Como pesquisador, trabalha principalmente com poesia brasileira e teorias da poesia. Atualmente, é professor de Teoria da Literatura e Literatura Comparada na UFMG, onde leciona, entre outras, disciplinas sobre crônica. 


\section{Contato}

28 DE NOVEMBRO DE 2019

Fala, Belúzio! 15:30

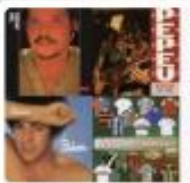

Flamengo - Homenagem ao

Campeão do Brasileirão e da

Copa Libertadores, 2019

Aí vai uma playlist pra você:

Flamengo - Homenagem ao Campeão

do Brasileirão e da Copa Libertadores,

2019 de Gustavo Cerqueira

Guimarães

https://open.spotify.com/user/

22nrijopsoz7lqgihqb36v5zy/playlist/

1uwbpaTkT5SbE2g2kwmumP?

$\mathrm{si}=\mathrm{X} 9 \mathrm{hFNABrQSC3vJi \_ ANKcYA}$

Opa, bacana! $15: 38$

Ema lista rubro negra vinda de um

atleticano... Já estou procurando

músicas tipo "Se gritar pega ladrão.
Quero falar rapidinho com vc ,

reestabelecer os afetos rs queria que

vc escrevesse sobre o mengao pra

FuLiA

Uai, pode me ligar. Mas não vou poder alongar, realmente estou na loucura aqui de fechar notas 


\section{Convocação}

D CONVERSAS STATUS CHAMAdAs

Editor Revista FuLiA

$<28$ de novembro 15:46 
3. Primeiras ideias

0 mais querido

Nação

Acho que a final da Libertadores

diz muito sobre as dimensões

continentais do Flamengo. A

mídia focou muito na viagem

dos cariocas até o Peru. Mas os

brasileiros das franjas do Brasil

foram lá. Felizes porque era mais perto para ver o time deles. A

torcida do Flamengo é um tanto

desterritorializada.

$\mathrm{Na}$ final da Libertadores, o

discurso nacionalista, muitas

vezes associado ao Flamengo, se

mostrou muito forte. A imagem

de que a Nação Rubro Negra é, no

plano futebolístico, a expressão do

verde amarelo. 
4. Preparativos para a apresentação

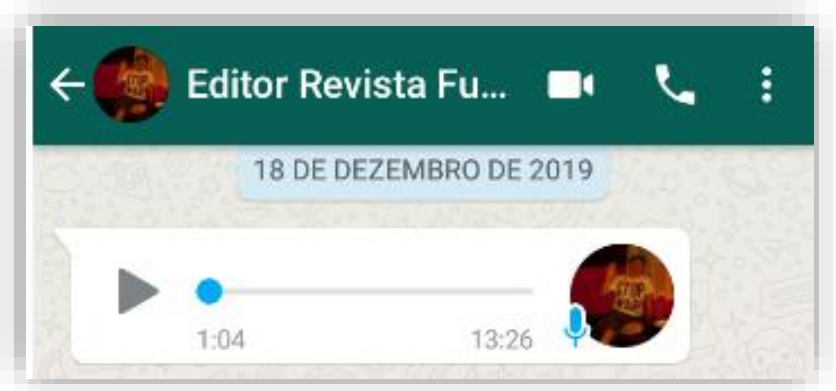

Transcrição do áudio:

Então, Rafa, é... agora, realmente, só tá faltando você, aqui, pra eu fechar a revista. Então, o quanto antes você me mandar, né... até o Natal, a gente fecha. Então, eu queria te pedir pra você mandar uma breve apresentação do.... do texto, né... e... um contexto, alguma coisa nesse sentido, e um breve currículo, um minicurrículo, destacando as relações com o texto, né, tipo, no caso aí, a crônica. Eu gostaria que você colocasse os jornais que você colaborou lá em... em Carangola, né. Eu já vi que você escreveu em um lá em... 2015... 2010... em 2015,Jornal da Cidade, né... é... e também que você colocasse outras publicações... né... tipo aquele livro sobre poesia que você publicou lá na Scriptum, né... é... enfim... falou? Qualquer coisa você me fala. Abraço. E tchau. 


\section{Apresentação}

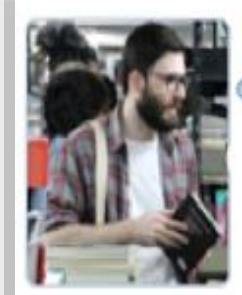

Resumo informado pelo autor

Rafael Fava Belúzio é professor de Teoria da Literatura e Literatura Comparada, na Universidade Federal de Minas Gerais, onde leciona, entre outras, disciplinas sobre crônica. Possui graduação em Letras (UFV) com formação suplementar em Filosofia (UFMG), mestrado e doutorado em Estudos Literários (UFMG). Já publicou mais de duzentas crônicas, atuando no jornal O Interior (2005-2013) e no Jornal da Cidade (2012-2015), ambos de Carangola/MG, e também colaborando no site LiteraturaBr (20162017). Como pesquisador, trabalha principalmente com Teorias da Poesia e Poesia Brasileira. É autor do livro Uma lira de duas cordas: 0 ritmo como elemento construtivo da binomia de Lira dos vinte anos.

(Texto informado pelo autor) 


\section{Primeiro treino}

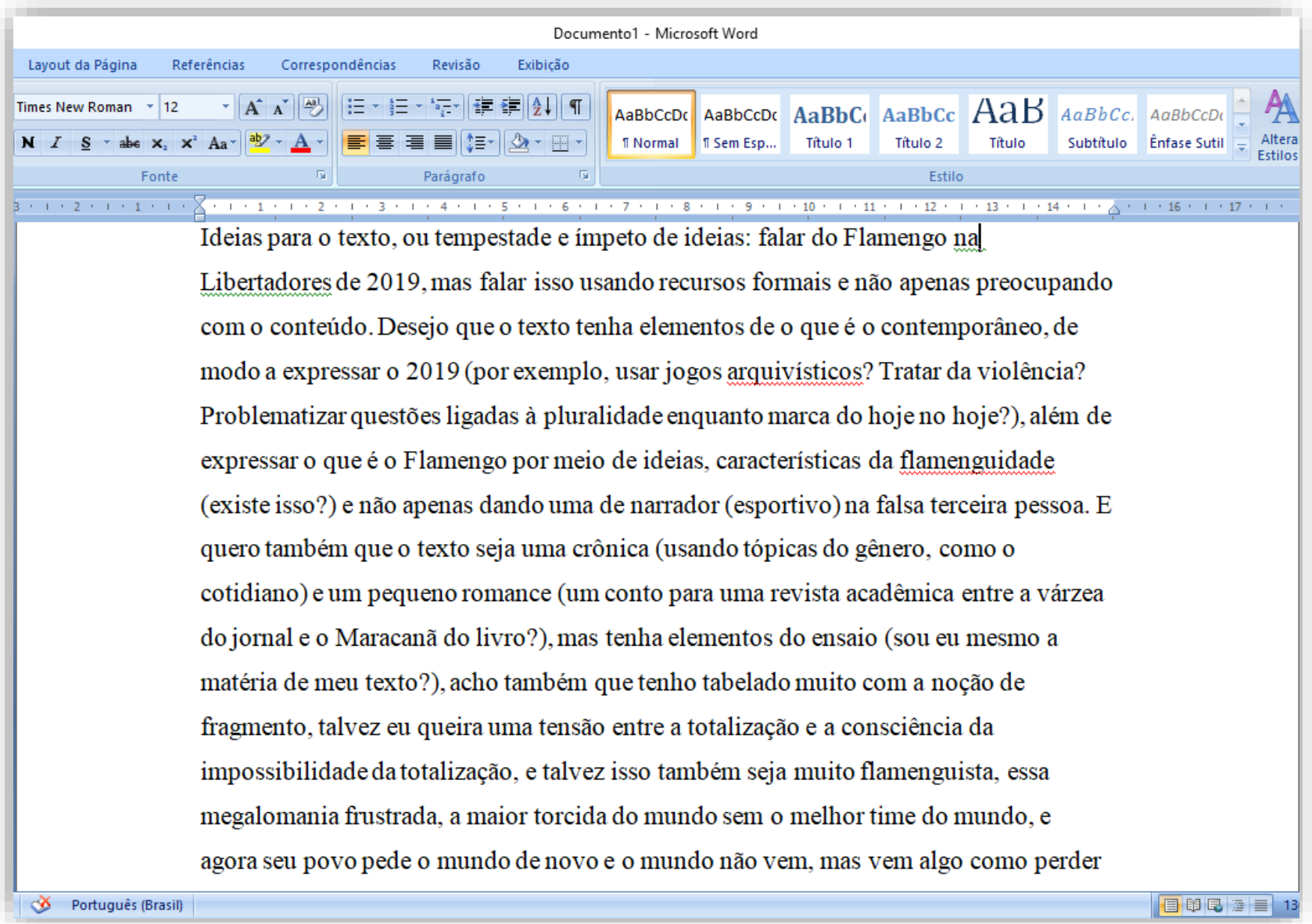




\section{Segundo treino}

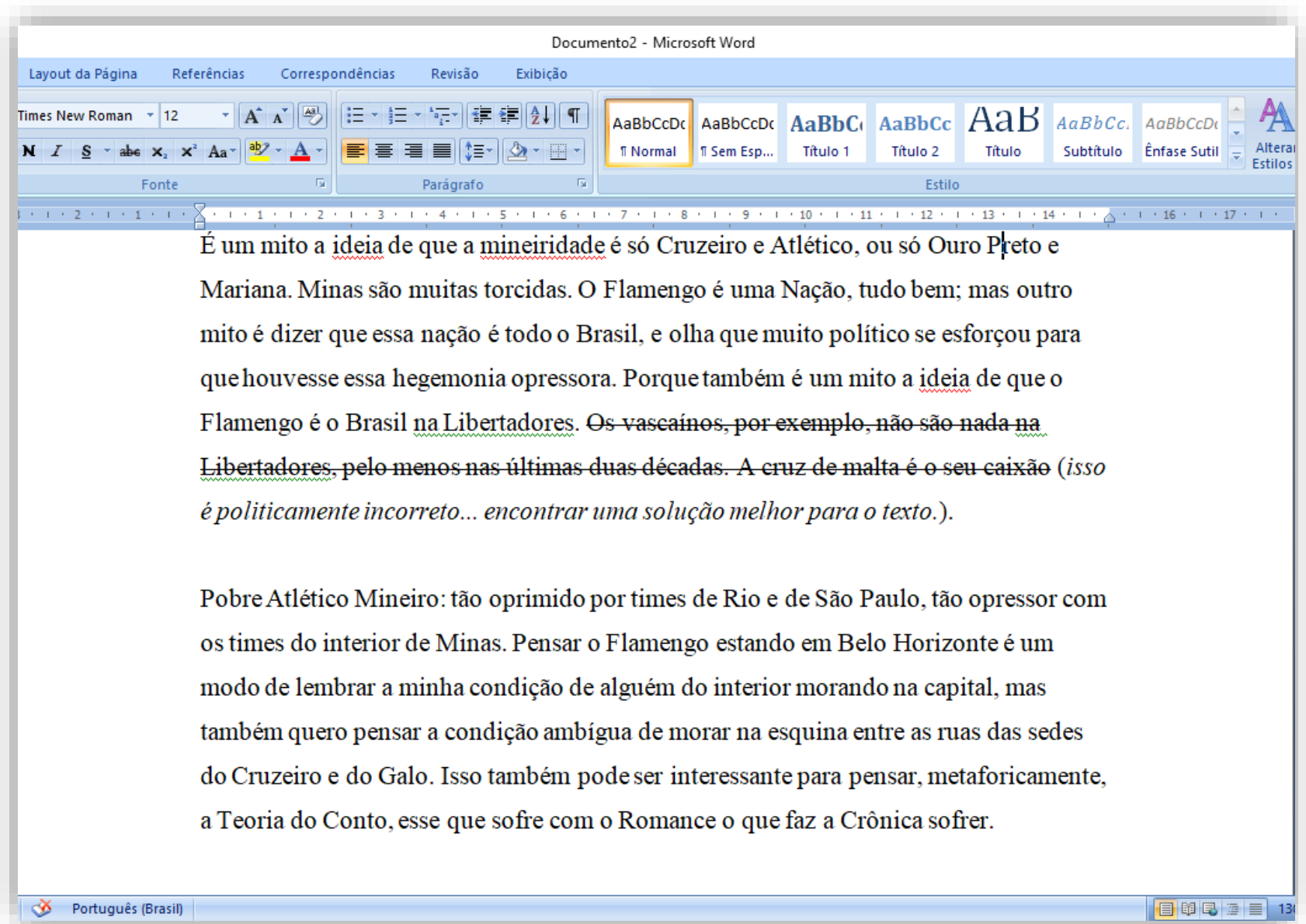




\section{Terceiro treino}

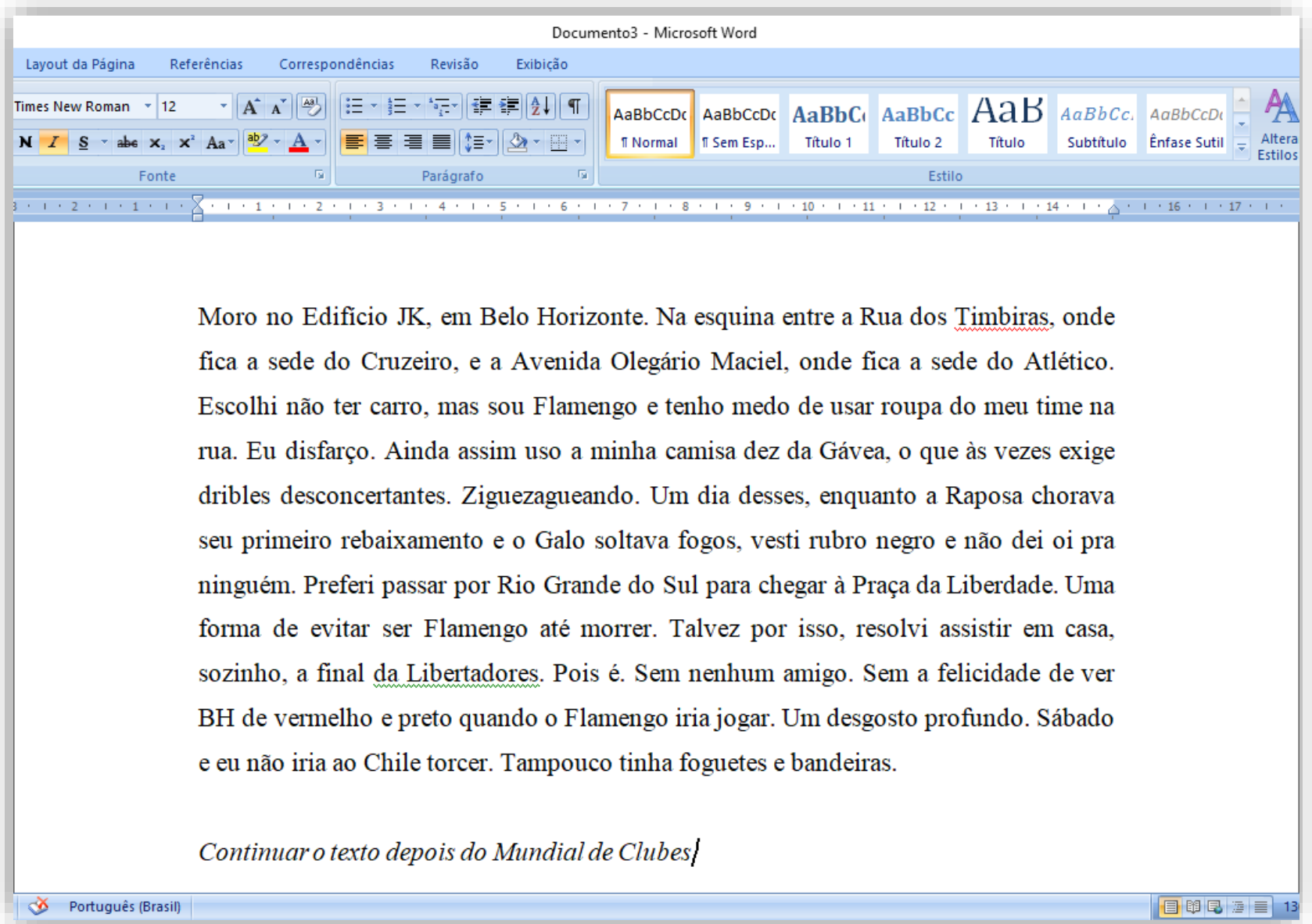


7. Coletiva de imprensa

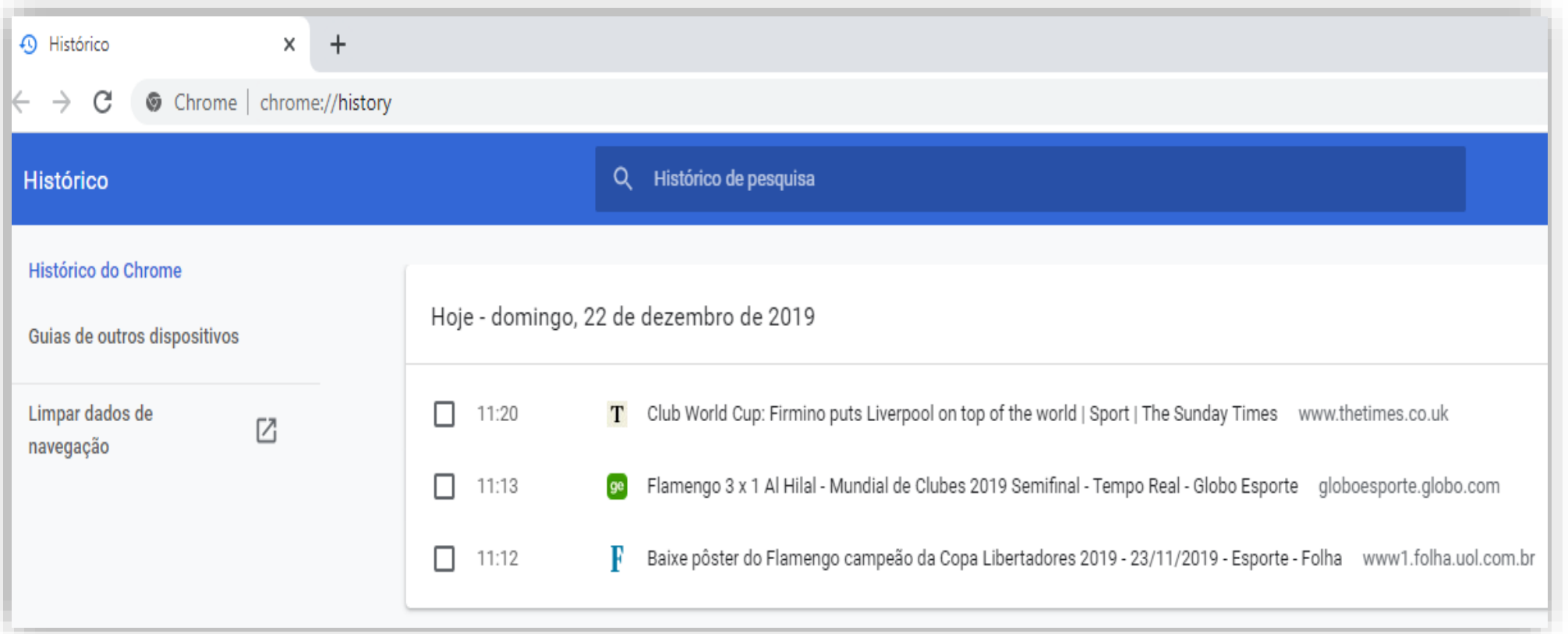


9. Falta ao treino 
11. W. 0 .

Para

fulia@letras.ufmg.br

$\mathrm{Cc} / \mathrm{Cco}$

Desistência

Prezado Editor, boa tarde.

Venho por meio deste e-mail agradecer o convite para envio de uma crônica sobre o Flamengo. O prazo a mim disponibilizado foi bastante razoável. O texto seguia em um ritmo também interessante. No entanto, desde ontem, quando o Flamengo perdeu o título mundial, mesmo tendo perdido jogando bem, considero que não será possível escrever a crônica. O luto é um estádio vazio.

Grato desde já pela compreensão.

Att.,

Rafael Fava Belúzio. 